International Journal of

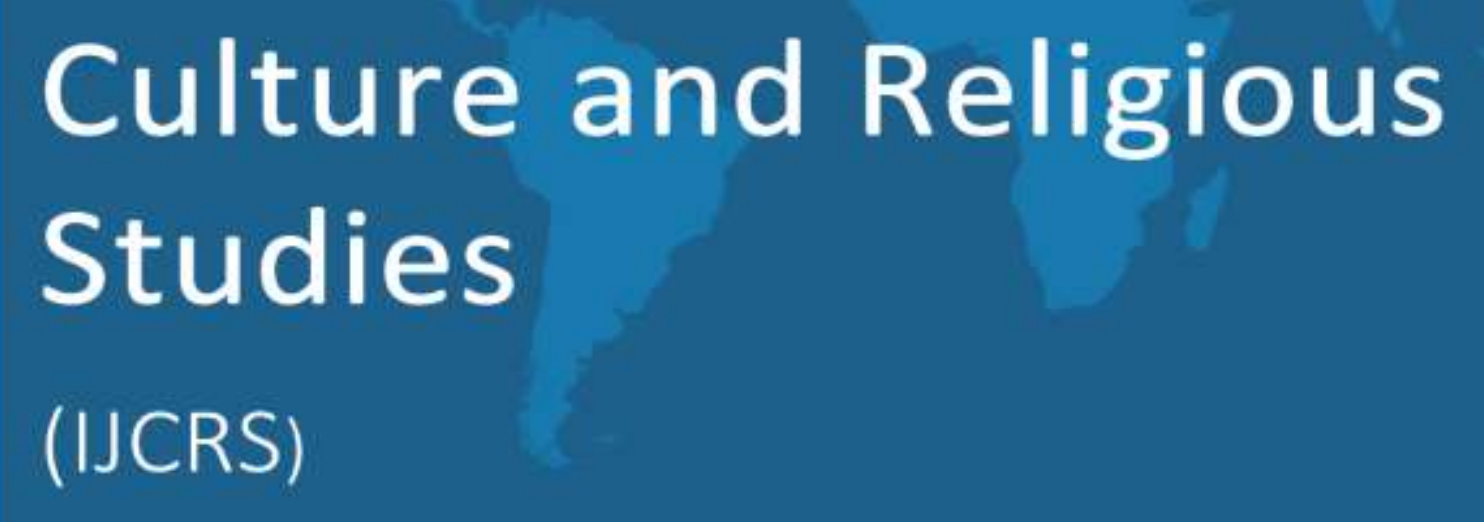

Culture and Religious

Studies

(IJCRS)
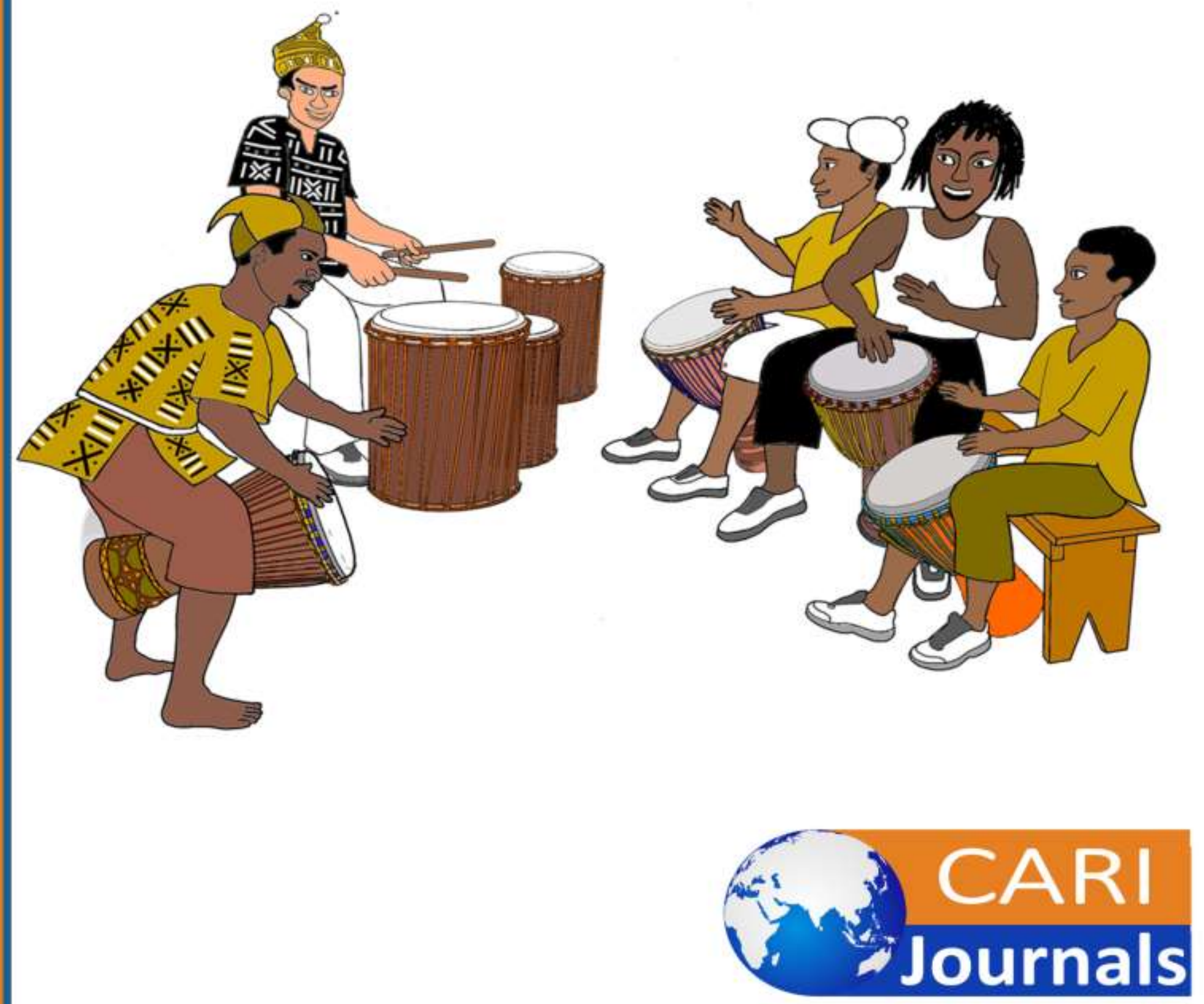


\title{
PERCEPTIONS OF INITIATION INSTRUCTORS AND PARENTS ON THE ROLE OF INITIATION IN CHARACTER BUILDING OF ADOLESCENTS: A CASE OF MOCHUDI VILLAGE, KGATLENG DISTRICT IN BOTSWANA
}

\author{
Tuelo Semme Ratsie \\ Ecloss Munsaka
}

University of Zambia, Department of Educational Psychology, Sociology, and Special Education

\begin{abstract}
Purpose: This study was aimed at describing the perceptions of initiation instructors and parents on the role of initiation in character building of adolescents.

Methodology: The study used a phenomenological approach. A sample of constituting 20 participants; 5 male initiation instructors, 5 female initiation instructors and 10 parents who have had their children going for initiation, all residing in Mochudi Village in Botswana. Purposive sampling, as well as snowball sampling were used to select participants. In-depth face to face interviews and a focus group discussion were conducted with the participants. The descriptive approach method (phenomenology) was used to interpret data.

Results: Findings revealed that initiation transforms an individual's thinking, feeling and acting, regulating his or her perceptions of reality to conform to that of society, thus initiation can be used to as a societal structure to transform and build the characters of adolescents.
\end{abstract}

Keywords: Adolescents; character building; interpretive phenomenological analysis, perceptions.

\section{INTRODUCTION}

Traditional cultural practices have been given great respect and attention by different communities of the world as they were believed to be the sources of values, beliefs and societal laws that kept a group of people glued together (Matsumoto \& Juang, 2013). In many African countries, including Botswana, initiation is regarded highly as a cultural activity that ushers one into a stage of adulthood and therefore regarded as a venerable practice that every young boy and girl must undergo. Daniel (2009) defines initiation as a rite of passage marking entrance or acceptance in a group or society. He further states that it could also be defined as a formal admission to adulthood in a community or one of its formal components. In an extended sense, initiation can also signify a transformation in which the initiate is 'reborn' into a new role. Van Gennep (1960), like other authors, defines initiation as a rite of passage which occurs when an individual leaves one group to enter another. He further identified that the rite of passage has three phases; the separation phase, the Liminal phase and the incorporation phase, which marks the end of the initiation ceremony 
International Journal of Culture and Religious Studies

ISSN 2789-3898 (Online)

Vol. 2, Issue No. 3, pp 19 - 30, 2021

WWW.carijournals.org

whereby initiates assume their "new" identity, one re-enters society with one's new status (see Munsaka, 2009).

Bakgatla-baga-Kgafela in Mochudi village is among the tribes that practiced initiation ceremonies and upheld the ceremony in high esteem as they considered it an integral social structure that moulded young people into individuals that best fit in society. It is believed that at the initiation school, young boys were taught things that transformed them into new individuals and that society appreciated them. The observation above is attested by Daniel (2009) who holds that initiates manifest a marked transformation of attitudes and behaviour because the society helps them through encouragement and sanctions. Daniel (2009) further suggests that the conviction that the initiates have emancipated beyond certain childish inferior and impure actions make them hold on to the teachings they received at the school. For a considerable period of time, Bakgatla-bagaKgafela have participated in initiation, until their paramount chief had a fall out with the government of Botswana and fled the country. Although, a regent chief was appointed to administrate all matters of the community, the initiation rite could not continue as the paramount chief was the only one who could send out the regiments to the 'school'.

Much research has already been conducted in this field focusing on Rites of Passage (Van Gennep, 1960), Continuity in the traditional initiation practice of boys and girls in contemporary southern Africa society (Matobo, Makatsa, Obioha, 2009), Sexual Objectification of Women in Female Initiation Rites (Munsaka, 2011), while others have analyzed rites of passage and their relation to Christianity (e.g. Daniel, 2009). Mosothwane, (1999) conducted a study on titled: "Ethnographic Study of Initiation schools among Bakgatla-baga-Kgafela at Mochudi (1874 - 1988)"; Setlhabi (2014) studied the Politics of Culture and the Transient Culture of Bojale; Bakgatla-baga-Kgafela women initiation in Botswana; Makgala, (2009) conducted a study on the Bakgatla-baga-Kgafela's initiates rites and the Modern Society. Matemba, (2003) studied the Pre-colonial Political History of Bakgatla-baga- Mmanaana of Botswana. While contributing significantly to the understanding of initiation rites, the above mentioned studies did not explore the role of initiation in character building of adolescents. In addition, some studies were conducted outside Botswana and thus less relevant to the context of Botswana. The current study, therefore, attempted to describe the perception of initiation instructors and parents on the role of initiation in building the character of an adolescent child. It was important to carry out this study because it would inform the community and the nation of Botswana about other structures that could be utilized in the up-bringing of children as well as an understanding of how initiation influences character building of adolescents.

\section{PURPOSE OF THE STUDY}

The purpose of this study was to describe the perceptions of initiation instructors and parents on the role of initiation in character building of adolescents.

\section{METHOD}

A qualitative study taking a phenomenological approach was used. The approach was most suitable for this study because of the need to get a deeper insight and understanding of the perceptions of initiation instructors and parents on the role of initiation in character building of adolescents. 

explanations and as free as possible from unexamined preconceptions and presuppositions. He concludes "the design focuses on the study of an individual's lived experiences within the world" (Frankel et al 2012, p. 463).

\section{Research participants}

The sample comprised a total of twenty participants, ten of whom were initiation instructors (five male and five female) and the other ten being parents who have had their children gone for the initiation rite, five of whom had sent male children and the other five had sent female children. All participants resided in Mochudi, Kgatleng District, a predominantly rural settling in Botswana.

\section{Data collection}

Semi-structured individual interviews and a focus group discussion were used to collect data. The interviews were used to give participants an opportunity to express their opinions and ideas freely in their own words while the focus group discussion was chosen to allow multiple perspectives as participants exchanged their view points as well as giving them an opportunity to share what they could have missed during the interviews.

All the interviews and focus group discussion were tape recorded to give the researcher an opportunity to refer to the recordings during analysis. It also helped the researcher to capture all the information even that she could have otherwise missed.

The researcher triangulated data collection methods; semi-structured interviews and focus group discussion to increase the credibility of the findings. Cohen, Manion and Morrison, (2000) explain that triangulation in qualitative research is used to increase credibility and validity of the research findings.

\section{Data analysis}

The data in the study were analyzed using the Interpretative Phenomenological Analysis (IPA) approach. Smith and Osborn, (2017) explain that the Interpretative Phenomenological Analysis approach utilizes both descriptive and interpretative approach and its aim is to explore in detail how participants are making sense of their personal and social worlds as well as giving the researcher an opportunity to get closer to the participants' personal world. The technique made it possible for the researcher to capture participants' perceptions on the role if initiation in character building of adolescents. The researcher transcribed all the interviews, read through them to familiarise herself with the perspectives of the participants, coded data and generated themes, and converged similar themes together and formulated concepts through which she presented the findings of the study.

\section{Ethical consideration}

The researcher obtained an ethical clearance from the University of Zambia Ethical Committee before embarking on data collection. This is in line with Kombo and Tromp (2006) who state that a researcher requires a research permit before embarking on the study. The letter was submitted to the customary court (Kgotla) where the researcher conducted the research study. Since the customary court was the main center of the research activities, the researcher sat with the chief to 
International Journal of Culture and Religious Studies

ISSN 2789-3898 (Online)

Vol. 2, Issue No. 3, pp 19 - 30, 2021

WWW.carijournals.org

map out the logistics of the interview. Participants were required to give their full consent to being interviewed and they were fully informed of their freedom to withdraw from the study any time they wished to do so without advancing reasons. Before the start of the interviews, the researcher had a meeting with the participants in which she shared the purpose of the study, the benefits of the study, and what could be the disadvantages of their involvement in the study, which was the fact that the interviews might take their time which they would otherwise use for their own chores/duties. Finally, participants were assured of confidentiality during the whole process of data collection and that the information gathered from them would be used only for the purpose of the study.

\section{RESULTS AND DISCUSSION}

The following sub-themes; support structure to the initiates, acquisition of skills, culture as the foundation of society, self-reliance and resilience, and womanhood and manhood were discussed under the overarching theme "initiation as a traditional school". The other themes discussed were as follows: initiation as a means of character building; convictions to stay true to the teachings of the initiation school, and need for continuation of initiation rites.

\section{Initiations as a traditional School}

Most parents had conceptualized initiation rites as "traditional schools" and therefore believed that every boy and girl must undergo it before they can be accepted by the society they live in as adults. In other words, initiation was a requirement for one to be recognized by society as a man or a woman. One initiation instructor in his late eighties said "In the past before these modern schools, initiation was our only school, respected and loved by all. Every parent sent his or her boy/ girl to the school in order to build them in to tomorrows' men and women. Personally, I was sent to the school by my parents and I am who I am because of it .... I am proud of it"

He also pointed out that although it has ceased in their village because of the absence of the Paramount chief, they desperately wanted it re- introduced because of the social ills that the society is going through and this is what he had to say: "Our community is no longer the community we knew. Youth is roaming the village doing as it pleases. There are so many problems, today you hear that so and so's child has killed a girl he claimed to love, tomorrow is another story so and so's child has raped an old woman. The stories we hear today were not there during our time because we were built in to men and women who were responsible not only to ourselves but also to the community, we live in."

Although some countries in Africa seem to have an age limit to entry in the traditional school like the Masaai of Kenya who conduct initiation every ten(10) years for boys of the ages between nine (9) and fifteen (15) years and the Bagisu of Uganda who send boys of the ages between fifteen (15) and twenty (20) years (Were, 1977), the Bakgatla - baga- Kgafela arrangement seems to be similar to the Balete and Bangwato, other ethnic groups of Botswana who conduct their initiation rite without entry age limit. One of the parents shared this "Our initiation rite arrangement has been like this ever since its inception, we all understand it and we simply flow with it just like your tribe of Balete. They also do not have age limit in to entry and this is to allow all boys and girls to take the manhood and womanhood ticket, even older men and women who did go have the 
International Journal of Culture and Religious Studies

ISSN 2789-3898 (Online)

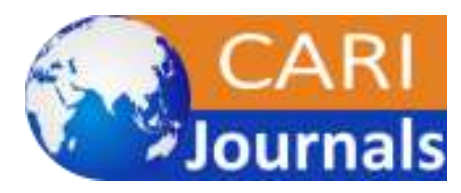

Vol. 2, Issue No. 3, pp 19 - 30, 2021

WWW.carijournals.org

opportunity to be re-aligned to the expectation of the society at the school. Said one of the interviewees."

\section{Support structure to the initiates}

Although initiation rite in Setswana culture is the mandate for the paramount chief, the society and the parents of the initiates have the obligation to support the exercise which its fruits of building the character of the individual benefit the entire society in as far as building the character of the individual is concerned. In Setswana culture, the child belongs to the parent by birth but is the responsibility of the society hence its direct or indirect involvement in the raising of the child.

The findings of the current study suggest that initiates are not just handed to the instructors, but are supported by their individual parents and members of society. The support parents render to their children runs from the food they eat while at the designated places to the attire they wear during initiation, and their parent's presence at the training sessions. Parents even take the trouble of being part of the process because they want to produce individuals who are credible, who meet societal standards in terms of what is expected from them upon completion of the school. One male parent had this to say "I had to be there for my son, to encourage him and ensure that he listen to his teachers. My presence also played an important part as he would also want to be seen to be towing the line and living to the expectation of the school." Another parent who had sent her child to the school and had an opportunity to go with her concurred saying "I supported my child by going with her to the training grounds every time she went for training. I played an important role of joining other women surrounding the initiates to create a wall around them to protect them against cold especially that the ceremony is conducted in winter, but most importantly, I wanted to ensure that she gets what is taught at the school by witnessing what is taught and emphasizing it at home."

The idea of supporting the initiates seems to be prevalent in other African communities that conduct initiation rites. According to Were (1977), at the end of the circumcision procedure of the Bagisu ethnic group of Uganda, boys are taken back to their homes where they are handfed for three (3) consecutive days before they are ritually washed and permitted to eat with their hand. Although it is not very clear whether the Bagisu of Uganda also accompanied their boys and girls to the secluded places like the Bakgatla-baga-Kgafela, they also provided them with some form of support that they deem necessary to ensure the success of the exercise. It is also clear that not only the parents felt the need to support their children, but the initiates themselves also felt the comfort of being supported by their parents which probably gave them the courage to forge forward with the school despite the challenges they encountered. This is what one female parent had to say about her child "My child who was doing form 2 at the formal school and also enrolled with initiation used to wake me up early during the week, asking me to accompany her to the initiation site to do two to three tasks before she could go to the formal school and I would agree." From the narrative above, it is clear that initiation rites are placed at the same level with formal schooling. It is deemed critical by both parents and children hence they would not want to miss the teachings of the day because they recognise the immerse positive impact that it makes on them.

\section{Acquisition of skills and knowledge}

Acquisition of knowledge and skills in the African perspective is an integral part of living and is considered a resilient factor through which individuals help themselves to deal with the problems 
International Journal of Culture and Religious Studies

ISSN 2789-3898 (Online)

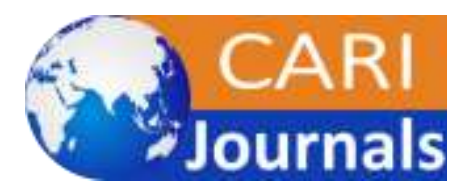

Vol. 2, Issue No. 3, pp 19 - 30, 2021

WWW.carijournals.org

they encounter in their lives. It is believed that it is the individuals' hands and wisdom that will make him or her forge forward despite the challenges they encounter in life, which averts them from some social ills such as theft and other vices. When encouraging children to learn skills that they can use to survive, parents usually say 'o tla a ja leswe la balekane ba gago fa o sa dirise diatla tsa gago' translated 'you will reap the trash of your age mates if you don't use your hands'. The saying means that if one does not use their hands to provide for themselves, they will depend on handouts from their age mates, thus emphasizing the importance of one's use of survival skills and knowledge to provide for their selves and their family. The participants shared that initiates were taught societal rules and regulations as the basis of their teachings. However, they were also taught some life skills and unique knowledge. The skills they were taught served to help them to survive some life challenges such as famine and alleviate other challenges such as poverty and diseases. Such skills were taught to both male and female initiates. One male instructor said "In our school, teaching life skills is a prerogative..... we instil the sense of farming to initiates so that they are able to provide for themselves and their families despite the challenges they encounter in life."

Another interviewee in agreement with the one him said "Our graduates have never disappointed us in terms of maintaining themselves and their families, because of these skills they have been able to live good lives."

The findings of the study have suggested that initiation rite prepared the initiates for a smooth life after their school. This could be the reason why parents in the current study observed that in the past there were not many cases of thefts, including burglary, shoplifting, because many people were able to put bread on the table for their families, which contrast to current situations where youth criminal activities were highly prevalent. Not only did initiation rites ensure that people learned how to provide for their families, it also kept them engaged physically and mentally and helped them to explore the different opportunities and their capabilities. Thus, in a way, initiation rites prevented young people from engaging into bad practices such as drug abuse, because they were always kept busy; they had no time to be idle. Women were also equipped with some skills that they could use to provide for their families. While men were taught ploughing and thatching houses among other things, women were taught how to build mud houses and taking care of the fields, knitting and sowing to make clothing for both their husbands and children. In support of the above statement another male initiation instructor who shared the same sentiments had this to say "Have you ever heard of someone who has been to the traditional school and yet could not put food on the table for his children or who does not have a shelter over his head? They were taught all these things at the school unlike the ones you train from your formal school." The observation is confirmed by Serpell quoted in (Nsamenang \&Tchombe, 2011) when he explains that hard work is virtue instilled in all children very early in life. He cited a Swahili proverb "mgaagaa na upwa hali wali mkavu" translated in English it says "a person who walks and searches around a beach never eats "dry rice". The focus here is the fact that one must strive hard for whatever they want. Serpell, quoted in (Nsamenang \& Tchombe, 2011) further explains that intelligence among Africans is understood in terms of four constructs being wisdom, aptitude, responsibility and trustworthiness. Thus, an intelligent man would be able to provide for his family.

\section{Culture as the foundation of a society}


Culture is an important aspect of socialization for any society. The findings showed that culture is pivotal in raising children if they were to fit well and live amicably with other members of society. One of the male initiation instructors shared his observation and said "We teach them the culture of their society because we do not want them to err, society is also expecting them to live to its expectation. We teach them the rules, norms, idiom, proverbs, values and stories and all these translate in to what the society wants from them." The observation is congruent with what Matsumoto and Juang (2013) posit that each culture's way of raising children through parenting behaviour, sleeping arrangements and educational systems represents that culture's way of ensuring that values and norms are transmitted to children, which serve to build their personality to societal expectations. It is therefore considered the foundation of every society and an agent that brings people together.

The participants further observed that Knowing the culture of one's society helps one to flow with the system as one will be able to fulfill societal obligations. It also reduces the chances to err which bring unnecessary conflicts and punishments. Rules, values and norms provide directions especially to young people (including adolescents) who do not have the experience and therefore thrive by being guided. Matsumoto and Juang (2003) concur when they say that all cultures give guidelines about how people are expected to behave through norms which are the accepted standards of behaviour for any cultural group. One female initiation instructor shared her observation and had this to say "Where instructions are well communicated and clear, there are less of conflicts and fights. Living according to societal expectation also makes them live a comfortable free live and urges them to learn more and master their culture which they pride themselves with." While a male initiate's parent said "Understanding and internalizing culture is important for our initiates because it builds their personality." The above caption is in-line with what Roberts, quoted in Matsumoto and Juang (2003) indicated when he said that aspects of personalities are created by performing repeated roles, thoughts, feelings and behaviours that occur in life. He further said that enculturation gradually shapes and moulds individuals' psychological characteristics including how they perceive their world, think about reasons underlying their actions and other people's actions, have and express emotions and interact with others. Clearly culture plays a crucial part in the up-bringing and socialization of children.

\section{Self-reliance and Resilience}

Findings from the current study further revealed that initiates were also taught self- reliance and resilience that were believed to empower them and give them the urge to pursue things that bring about a positive change in their lives. One female initiate's parent said "they learn the different ways in which they can provide food and other necessities to their families. They are taught to make ends meet and survive the predicament without necessarily encroaching into other peoples' territories."

Another interviewee, a male initiation instructor who believes parents have the obligation to build resilience in initiates said this "We train them to walk with their chest out, to believe in themselves so that they can stand up for themselves and their families. They need us to shape their personality as well as supporting them in order for them to be resilient." The observation above is in-line with what Nsamenang and Tchombe (2011) also observed when they contend that resilience develops from an interaction of personal characteristics. They further said that it is taught, encouraged and 
International Journal of Culture and Religious Studies

ISSN 2789-3898 (Online)

WWW.carijournals.org

Vol. 2, Issue No. 3, pp 19 - 30, 2021

enhanced through idioms, proverbs and stories and that each culture has a way of teaching and encouraging them.

\section{Manhood and Womanhood}

According to the participants in the current study, in the past, circumcision was only carried out on people who went to the initiation school and that marked and separated men who had attended initiation school from those who had not attended the school. They further alluded that it also qualified them to the status of manhood. Daniel (2009) confirms what they said when he pointed out that in the eyes of society, initiation is the criterion for growing up. Daniel further observes that circumcision is aimed at giving a physical mark on the body which is coupled with the concomitant instruction in modifying the personality of an individual in a manner visible to society. Daniel reiterates that initiation is a means of permanent differentiation. A male initiation instructor shared this "In the past our graduates were given a mark that separated them from the rest of other men, a mark that qualified them to the manhood;"

A male initiate's parent who wanted to share the respect and honour that was accorded the initiates lamented "Even in our Kgotla gatherings when the paramount chief had called us, he would ask men to sit one side and boys to sit the other side and all knew what he was talking about."

Although every man is encouraged to undergo circumcision, especially in the wake of the HIV/AIDS scourge and modernization, those men who went to the traditional initiation school can still be identified from the rest by their conduct. Another male initiate's parent shared his observation "Apart from circumcision, a man and a woman who has been to the initiation school is always different from the one who has never been to the school yet circumcised. They are taught many things that set them apart from any other men, such as looking after their wives and raising their children upon getting married and the same thing applies to girl initiates."

\section{Initiation as a means of character building}

During the interviews and focus group discussion, participants revealed that initiation moulds and shapes one's personality; it creates a sense of shame that keeps the conscience in check and builds a morally upright person. Participants reiterated that initiation weeds out bad behaviour, thoughts and perceptions that are not in-line with societal rules, norms and values. One participant said "It is shame that builds one's morals. If one cannot get ashamed of getting pregnant at a young age, roaming the streets drunk, shouting insults, that person's conscience is dead and his morals would not be conforming to societal expectations nor set standards"

The above observation concurs with Van Gennep (1960) observation that the initiation rite is expected to modify the personality of the individual in a manner that will be visible to all. Daniel, (2009) affirms, as does Munsaka (2009) Van Gennep's observation when he said that initiation is targeted at changing a person's thinking, feeling, and acting with a view to regulating his perception of reality to conform to that of society, adding that society makes him adopt and interiorize a set of values which constitute society's world view.

The participants also shared that the initiates are taught societal rules, norms and value which provide guidelines as what is expected of them by society. They said that they have to internalize them and know them by heart as well as living them, adding that the rules, norms and values are 
International Journal of Culture and Religious Studies

ISSN 2789-3898 (Online)

Vol. 2, Issue No. 3, pp 19 - 30, 2021

WWW.carijournals.org

passed on to the initiates through different forms such as teachings, songs and stories that are told and explained to the initiates so as to clarify what they could have not understood. Participants observed that it is those stories, norms and values that transform initiates' thinking, actions and the way they perceive things. The above observation is confirmed by Daniel (2009) when he argues that initiates are taught to think about the community and see the world as it sees it.

Also explained by the participants, initiates are subjected to rigorous training that challenges their endurance and strengthens their will power. The participants asserted that not only does the training strengthen their endurance and their will power, it also moulds their behaviour in that it changes their personality which later informs their conscience which time and again they make reference to especially where they are not sure whether what they want to do is right or wrong. They further explained that various activities are used to transform the boys and girls. One of the participants observed "Every song has a meaning, the song 'Mmamodisanong o o mangana $o$ phakeletse metsi o jeleng?' Directly translated 'Mmamodisanong the girl who never listen, why have you drunk some water so early?', it is asking girls why they have fallen pregnant at a tender age. The song makes them introspect and those who had started seeing boys get cautioned of what is likely to come out of their relationships and they usually abandon them. Apart from the songs they are taught, punishment is also metered when they have erred to correct the unwanted behaviours such as refusing to take instructions, hurling insults, failing to carryout tasks and any other behaviour that is deemed unacceptable to society. Participants disclosed that initiates are whipped with maretlwa sticks or the branches of moologa that is carried around and used to provide cover for them in case of girls. Another interviewee who is in agreement with the one above said "We whip the hell out of their heads and if there is anyone stubborn by the time they graduate, they will have earned themself some stripes like a zebra."

The participants suggested that there is positive behaviour influence that initiates get from one another. Once at their training grounds, they develop a team spirit and they support each other. They also share ideas and help each other to complete tasks and encourage each other to forge forward and change their behaviour to the requirement of the school so that they can all complete the training successfully. One of the interviewees had this to say "Our school is fond of the team spirit that prevails among our initiate trainees. They care about the progress of each other by ensuring that they give each other support thus helping them to transform by evaluating each other during their own spare time."

\section{Convictions to stay true to the teachings of the initiation school}

The findings have suggested that upon completion of their training, initiates have a strong conviction to remain true to the teachings they received. It also comes out that the conviction is brought about by some of the activities that they carry out at the training as well as the experiences and the observations from those who went to the school earlier. Circumcision that is done to the boys towards the end of their training seems to bring immerse convictions to stay true to the teachings to the initiates. Daniel (2009) authenticates the above observation when he asserts that it gives them a permanent mark that differentiates them from the rest of other boys and also marks their inception to the status of men. The participants further alluded that upon completion of the ceremony, initiates are no longer boys but men, and the ceremony ends by being given a regiment name (mophato) by the paramount chief in the presence of multitudes of people who would have 
International Journal of Culture and Religious Studies

ISSN 2789-3898 (Online)

Vol. 2, Issue No. 3, pp 19 - 30, 2021

WWW.carijournals.org

come to witness and celebrate their confirmation of the status. One female initiate's parent said this in regard to the regiment name "Leina leo ke dikgole, le a tlotlwa, le a dibelwa." Translated he said "that name is as good as a prison sentence, and it must be respected" and as member of the regiment if you err you have brought disrepute to the group and your actions are punishable according to the laws of the traditional school. Van Gennep (1960) corroborates the observations of the initiation instructor when he asserts that the understanding that the new position is higher, superior and more perfect in comparison to the earlier one makes it easier for the individual to take the ordeals of the initiation.

\section{Initiation Continuity}

The findings revealed that initiation is an integral part of a society and as such should co-exist with the community. Participants emphasized the important role that initiation plays in the society, indicating that as much as it builds the character of an individual person, it also builds the society within which those people live. Regiments work with the paramount chief and the headmen; they can be assigned tasks to do in order to bring some order in the village or help alleviate a problem. One initiation instructor and also a headman had this to say "Do you see those silos? They were built by the one of the regiments and we are still using them today to store produce for the community to be used during the drought season? Another regiment, cleared and made the road from Mochudi to Sikwane."

From the quote above it seems that initiation brings people together as they tend to see things from each other's point of view and therefore have little or no differences. The findings have shown how deeply rooted the Bakgatla-baga-Kgafela are in their culture which gives respect and honour to initiation which they believe their society is as it is because of it and therefore believe it should continue. One female initiation instructor shared her observation "The importance of initiation in building the character of a child cannot be looked at face value; we have had some other tribes bringing their children here to be initiated with ours because their parents have seen the tremendous work initiation do on both boys and girls; and adults ......it must continue. "She further explained that some families have failed to raise children according to societal expectations, hence available societal structures must be utilized to normalize the situation, emphasizing that children are also an asset to society and should be cared for by all. Participants also lamented on the cessation of initiation ceremonies since the paramount chief fled the country the country for South Africa and how moral decay and bad behaviour have been on the rise. The community attributes the rise in the said vices to the non-training of initiation, believing that the reintroduction of initiation is the only thing that could restore decency to society.

\section{CONCLUSION}

The study has found that initiation transforms an individual's thinking, feelings and acting, regulating his or her perception of reality to conform to that of the society. In addition, the findings have revealed the differences in the general conduct and behaviour that exist between boys and girls who went for initiation rite and those who did not as well as the challenges that parents whose children did not attend initiation rite grappled with. 
International Journal of Culture and Religious Studies

ISSN 2789-3898 (Online)

Vol. 2, Issue No. 3, pp 19 - 30, 2021

WWW.carijournals.org

The wish for continuity of the initiation schools as a societal structure that has had an enormous impact on the transformation and character building of growing boys and girls who continuously require guidance was also revealed. Clearly, initiation is a credible societal structure that transforms individuals' character from their old childish unacceptable behaviours to new and mature socially acceptable behaviours. It therefore suggests that initiation can be used as a societal structure to transform and build the character of adolescents, to change them from their inferior earlier life to a superior one that would earn them a superior societal status as well brought up men and women.

\section{REFERENCES}

Cohen, L., Manion, L., \& Morrison, K. (2000). Research Methods in Education. Brit J Educ Stud 2000; 48:446.

Creswell, J. W. (2013). Research Design-Qualitative, Quantitative, and Mixed Methods Approaches. Califonia. SAGE Publications.

Daniel, K. (2009). An Analysis of the Rite of Passage and their Relation to Christianity. International Journal of Sociology and Anthropology: Vol.1 (8) pp.156 -166.

Fraenkel, J. R., Wallen, N. E \& Hyunh. H. (2012). How to Design and Evaluate Research in Education. New-York: Mc Graw-Hill Companies.

Kapambwe, M. (2020). An introduction to Zambia's Luvale People. Culture Trip. Retrieved 25th July, 2020.

Kombo, D. K.\& Tromp, D. L. A. (2006). Proposal and thesis writing: An introduction $\left(7^{\text {th }}\right.$ Edition) Nairobi. Paulines' Publication.

Makgala, C. J. (2009). The Bakgatla-baga-Kgafela's initiates rites and the Modern Society: Published by Botswana Society

Matemba, Y. H. (2003). The Pre-colonial Political History of Bakgatla-baga- Mmanaana of Botswana. C1600-188. Botswana Notes and Records. Vol. 35: pp.53-67 published by Botswana Society.

Matobo, T.A., Makatsa, M \& Obioha, E. E. (2009). Continuity in the traditional initiation practice of boys and girls in contemporary southern Africa society. Stud tribes tribals, 7(2):105 113: Lesotho.

Matsumoto, D. \&Juang, L. (2013). Culture and Psychology. Belmont: Wadsworth Publishing Company.

Mosothwane, M. N. (2001). An Ethnographic Study of Initiation schools among Bakgatla-bagaKgafela at Mochudi (1874 - 1988). Pula: Journal of African Studies. V15, No.1.

Munsaka, E. (2011). Sexual Objectification of Women in female Initiation rites: The case of Chisingu female Initiation rites. (Pp335-348). Conference: Re- imagining Psychology: Proceeding of 2009 Southern African Students. 
International Journal of Culture and Religious Studies

ISSN 2789-3898 (Online)

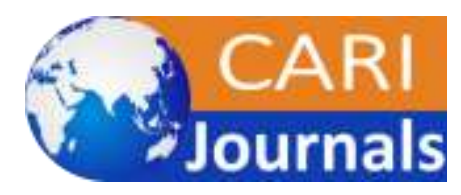

Vol. 2, Issue No. 3, pp 19 - 30, 2021

www.carijournals.org

Munsaka, E. (2009). Understanding school dropout among adolescents in a rural site of southern Zambia., open.uct.ac.za, http://open.uct.ac.za/handle/11427/11125.

Nsamenang, A. B. \&Tchombe, T. M. S. (2011). Handbook Of African Educational Theories and Practices: A Generative Teacher Education Curriculum. Cameroon: Human Development Resource Centre.

Setlhabi, K. G. (2014). The Politics of Culture and the Transient Culture of Bojale: Bakgatlabaga-Kgafela women initiation in Botswana: Journal of Southern Africa Studies. 40(3)

Smith, J.A \& Osborn, M. (2017). Interpretative Phenomenological Analysis. Birkbeck institutional Research online. Stud 2017; 47: (53-80) Google scholar.

Van Gennep, A. (1960). The Rites of Passage. (Trans. M. B. Vizedom and G. L. Caffe.): Chicago: University of Chicago Press.

Were, G. S. (1977). The Historical Origin of the Circumcision among the Bamasaba. TransAfrican Journal of History. Vol.6/7, pp129-141(13pages) 